to yield maximum information concerning economic and settlement patterns. Analyses and interpretation of information recovered from these sites must utilize to the full the techniques of all the disciplines involved.

The complexity of the study of Bantu origins makes it essential that there should be maximum collaboration between the relevant disciplines and institutions. This will need to be achieved through careful consultation and co-ordination in the planning of research, and through the regular exchange of staff and students. Visiting studentships and professorships need to be established on an international basis.

In the interpretation of archaeology and linguistic data it is of great importance to use the detailed evidence about the development of society and material culture during the past 500 or 600 years. It was noted that the trend in research in traditional history is increasingly towards intensive work in particular linguistic communities and that, since in most of Africa these communities are small, research work must justify the heavy investment in linguistic training by working over a large chronological span in geographically limited areas. In all such studies scholarly presentation of the primary evidence is at least as important as the work of interpretation, and most research projects need to be conceived in terms of three or four years of research at dissertation level, including a substantial period spent in the field.

There is need to train ethnographers to specialize in those aspects of culture which are relevant to the archaeological and historical understanding of the African past: e.g. distribution studies, studies of patterns of settlement and of trade, the manufacture and use of artefacts, attitudes towards these and their nomenclature, and the technology of iron working.

The most definitive evidence concerning the origin and evolution of cultivated plants may be expected from the field of archaeology. Critical botanical evidence is frequently ignored or of little use for lack of efficient means of positive identification.

\title{
Centre of African Studies, Edinburgh: Seminar on Witchcraft and Healing
}

AN interdisciplinary seminar on this subject was held at the Centre of African Studies, University of Edinburgh, on 14 and Is February 1969 , under the joint chairmanship of Dr. R. G. Willis and Mr. Christopher Fyfe.

Papers were read and discussed on the following subjects: Healing as a Psychosomatic Event (the Revd. Fred Welbourn); Sickness Behaviour in Western Nigeria (Dr. Una Maclean); Persistence of Supernatural Beliefs among Ghanaian University Students (Professor Gustav Jahoda); The Political Role of Witchfinding in Malawi during the Crisis of October 1964 to May 1965 (the Revd. Dr. Andrew Ross); and The Horseman's Word: a Secret Ploughman's Cult in nineteenth-century Scotland (Mr. Hamish Henderson).

\section{Centre international d'Etudes et de Recherches sur l'Intégration Economique de l'Afrique}

IN October 1968 a meeting was held at the Faculty of Law and Economic Sciences in Paris to establish an 'Association Internationale pour le Développement, en Afrique, des Sciences humaines Appliquées' (AIDASA) with the object of promoting the development of applied human sciences relating to Africa and the dissemination of information in this field. It will seek to secure profitable applications for socio-economic growth in Africa of scientific studies already undertaken or being planned. The Association was established under the Presidency of Professor Gaston Leduc of the Faculty of Law and Economic Sciences and Professor Bruno Tohngodo, of the Institut de Droit Appliqué, was elected Secretary-General.

Considering that there was a lack of a specialized scientific organization with reference to researches directed towards the development of common regional markets in Africa and 